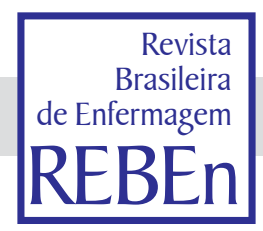

REFLEXÃO

\title{
Uma reflexão sobre a cultura organizacional à luz da Psicanálise
}

\author{
A reflection about organizational culture according to Psichoanalysis' view \\ Una reflexión sobre la cultura organizacional bajo la visión de la Psicoanalísis
}

\author{
Maria Lúcia Alves Pereira Cardoso' \\ 'Universidade Federal de São Paulo, Departamento de Enfermagem, Grupo de Estudos e \\ Pesquisa em Administração dos Serviços de Saúde e Gerenciamento em Enfermagem (GEPAG). São Paulo, SP
}

Submissão: 04/12/2007

Aprovação: 3/01/2008

\section{RESUMO}

Este artigo faz uma reflexão sobre os pressupostos universais da cultura da espécie humana, revelados por Freud, como subsídio para análise dos pressupostos da cultura organizacional, segundo Schein Que indica, em seu artigo de 1984, Que para poder decifrar a cultura organizacional, o estudioso não pode ater-se aos artefatos (visíveis) ou aos valores (percebíveis), mas deve mergulhar mais a fundo e identificar os pressupostos Que constitúem a base da cultura organizacional. Estes pressupostos penetram no campo do estudo do interior do indivíduo, assunto da competência da Psicanálise. Assim, as definições de Freud apóiam-se nos pressupostos básicos da cultura humana e a sua concordância com os paradigmas da cultura organizacional relacionados por Schein.

Descritores: Psicanálise; Cultura organizacional; Cultura.

\begin{abstract}
This article aims at submitting a reflection on the universal presuppositions of human culture proposed by Freud, as a prop for analyzing presuppositions of organizational culture according to Schein. In an article published in 1984, the latter claims that in order to decipher organizational culture one cannot rely upon the (visible) artifacts or to (perceptible) values, but should take a deeper plunge and identify the basic assumptions underlying organizational culture. Such pressupositions spread into the field of sttudy concerning the individual inner self, within the sphere of Psychoanalysis. We have therefore examined Freud's basic assumptions of human culture in order to ascertain its conformity with the paradigms of organizational culture as proposed by Schein.
\end{abstract}

Descriptors: Psychoanalysis; Organizational culture; Culture.

\section{RESUMEN}

Este artículo pretende presentar una reflexión sobre los presupuestos universales de la cultura humana revelados por Freud, en tanto contribución al análisis de los presupuestos de la cultura organizacional según la óptica de Schein. En su artículo de 1984, este último señala Que para descifrar la cultura organizacional, el estudioso no puede atenerse a los artefactos (visibles) o a los valores (perecibles), sino que debe profundizar e identificar los presupuestos Que conforman la base de la cultura organizacional. Esos presupuestos penetran en el campo del estudio del interior del individuo, un tema que le compete al Psicoanálisis. Por lo tanto, buscamos las definiciones de Freud sobre los presupuestos básicos de la cultura humana para verificar su concordancia con los paradigmas de la cultura organizacional señalados por Schein.

Descriptores: Psicoanálisis; Cultura organizacional; Cultura.

Correspondência: Maria Lúcia Alves Pereira Cardoso. Rua Cláudio, 213, apto 172, CEP: 05043-000, São Paulo, SP. 


\section{INTRODUÇÃO}

Embora Schein tenha apontado os pressupostos básicos como elementos de natureza inconsciente na cultura organizacional, não explorou a Questão do inconsciente Que o remeteria aos estudos da Psicanálise, pois o inconsciente é o "objeto privilegiado" desta disciplina ${ }^{(1)}$.

A Psicanálise "desenvolve o nosso interesse pelo Que é excluído do cenário da história, do pensamento disciplinado e vigilante, e nos ajuda a entender os processos sociais, entre os Quais os modos de controle social, como podem ser entendidas as organizações e a cultura." Assim, a lista abaixo apresenta sete tipos de sistemas de controle social, a maior parte deles recorrentes também nas organizações ${ }^{(1)}$.

O controle físico: fundamenta-se nos modos de violência, de opressão, exploração, repressão, etc., e na forma de controle Que exerce ação direta e intensa sobre o grupo social, procurando dobrar, indiferentemente, os corações e os corpos, em geral ao mesmo tempo.

O controle burocrático: refere-se ao controle do trabalho e do rendimento. É importante Que o indivíduo revele-se um instrumento dócil, obediente às instruções Que lhe são dadas e ao plano global da organização.

O controle por resultados: ocorre pela competição econômica, é sua forma mais sutil e moderna de controle. A ideologia do sucesso nos negócios e na vida privada e pública é sinal de sucesso a ser invejado pelos demais, como manter-se na corrida e não ser desacreditado.

O controle pela democracia: o Estado, acreditando ser a mais pura expressão da vontade popular, começa a indicar ao povo Quais devem ser seus desejos (a ditadura das ideologias nos partidos, assim como a ideologia empresarial Que assume aspectos de uma religião).

O controle pelo amor: é a total identificação ou a expressão de confiança. Este controle ocorre de dois modos fundamentais: o fascínio, próximo da hipnose, (ideal de ego) e a sedução (jogo das aparências

O controle por saturação: verifica-se pela repetição infinita de um único texto, isto é, pela uniformização e monopólio do discurso social, buscando conduzir as manifestações e as condutas dos indivíduos do grupo social ou das massas, e privando-os de seus próprios desejos e meios de expressão, gerando, em um primeiro momento a apatia. Em seguida, a aceitação incondicional do discurso monopolizado.

O controle pela dissuasão: ocorre pela instauração de um aparelho de intervenção, demonstrando força, mesmo Que não seja para usá-la, como se deu durante a guerra fria. Ocorre também pelo jogo e ameaça de demissões nas empresas, Que levam cada indivíduo a se fechar em seus problemas pessoais e familiares, em uma verdadeira privatização de conduta.

Conforme esses referenciais, as organizações são culturas, e como tal seus valores e artefatos são construídos sobre seus pressupostos básicos. Por outro lado, elas participam da formação e modificação dos pressupostos da cultura humana, mais amplos, emprestando elementos de seus próprios pressupostos básicos.

A seguir dois trechos de autores importantes e distantes um do outro, tanto no tempo como nos campos do conhecimento, demonstram a afirmativa apresentada.

As empresas conseguiram tornar universais alguns dos pressupostos de sua cultura: a eficácia, o desempenho, o sucesso e a visão do mundo como um universo de comportamentos estratégicos $^{(2)}$

Já vimos Que a forma atual do capitalismo global é insustentável dos pontos de vista social e ecológico. O chamado 'mercado global' nada mais é do que uma rede de máouinas programadas para atender a um único princípio fundamental: o de Que o ganhar dinheiro deve ter precedência sobre os direitos humanos, a democracia, a proteção ambiental e QualQuer outro valor ${ }^{(3)}$.

\section{METODOLOGIA}

Neste artigo, a metodologia pautou-se na análise comparada dos textos de Schein e Freud, com foco nos pressupostos básicos da cultura organizacional e da cultura humana. Como apoio referencial utilizado ${ }^{(1)}$ para fazer emergir, mais claramente, o extrato dos enfoques de Freud no tocante aos pressupostos básicos da cultura universal. Com base nesses pressupostos, são analisados os paradigmas culturais oferecidos por Schein e a identificação das semelhanças entre essas abordagens.

\section{RESULTADOS}

\section{Fundamentos da Cultura Humana na Visão de Freud}

Para Freud, a cultura humana é constituída por tudo o Que na vida do homem representa uma superação de seus limites ou condições zoológicas. Primeiro, é importante notar Que, como decorrência, a cultura compreende todo o saber e o poder que os homens coneuistaram para dominar as forças da natureza e obter os bens necessários para satisfazer suas necessidades. Segundo, a cultura compreende, igualmente, todas as organizações necessárias para regular as relações Que os homens mantêm entre si e, particularmente, a distribuição dos bens materiais alcançáveis e não a diferencia de civilização.

A organização social e o mundo das representações coletivas estão intimamente relacionados, porQue têm a mesma função: garantir a produção dos meios de subsistência ante uma natureza Que, via de regra, se apresenta plena de hostilidades.

Como conjunto de recursos para o domínio da natureza, a cultura não é tanto ameaçada pelo desejo de obter e manter uma distribuição mais justa dos bens necessários à sobrevivência, já Que isso não põe em risco sua existência como tal. A cultura é sobretudo ameaçada pelas tendências destrutivas, anti-sociais e propriamente anticulturais Que surgem, inevitavelmente, dos sacrifícios que ela impõe à organização pulsional de seus membros, visto Que ser considerada é necessariamente repressão.

Dessa maneira, parece que o homem descobre que é por meio do trabalho Que pode tornar sua sorte mais satisfatória no mundo. Eros e Anankê, amor e necessidade, são assim os pais da cultura. Este é um dos pressupostos fundamentais da cultura humana.

A origem do amor não é menos sexual, mas este passa a se manifestar como laço afetivo, garantindo uma coesão mais intensa do Que a comunidade de interesse do trabalho, embora ao preço de um conflito com a tendência totalitária da pulsão 
erótica.

A família tende a conservar-se unida e a desinteressar-se do grupo, caso não intervenham desvios da libido Que visem a diminuir a intensidade dos laços familiares e a unir mais fortemente os membros das diversas famílias, por intermédio da identificação e do amor inibido em seus fins (rituais religiosos, de iniciação, organizações). Este é outro pressuposto universal da cultura humana.

A cultura exige de cada membro da coletividade uma renúncia cada vez maior a seu erotismo. Na verdade, de um processo Que se inicia com a proibição de incesto na época totêmica e Que vai até a energia desviada da libido em Que a cultura se constrói. Mesmo Que essa canalização pareça ter diminuído, a partir dos anos de 1960, a continuidade da renúncia parece continuar necessária à manutenção do edifício da civilização e este continua a ser um pressuposto universal da cultura humana.

O fato favorece e fortalece a reciprocidade na identificação; entretanto, também, a rivalidade é provocada. Fica claro Que a identificação de cada um com o líder é o fundamento da identificação recíproca, seja nas massas desorganizadas, seja nas organizadas, este é outro pressuposto universal da cultura humana.

A culpabilidade interiorizada representa a garantia mais perfeita da submissão. No nível indivídual, o superego, como sentinela interior, é a melhor garantia de conformidade. No nível social, de geração para geração, é reproduzida a mesma culpabilidade inconsciente, base última da coesão social. Embora trate essa Questão também de outra forma em Psicologia das massas e análise do ego, este também é um pressuposto universal da cultura humana ${ }^{(4)}$.

O processo Que se pode chamar de "enamoramento", pelo Qual um objeto é colocado no lugar ideal do ego, enquanto, na identificação, o objeto instala-se no próprio ego. Este foi o primeiro processo pesquisado na $\operatorname{TLTX}^{(5)}$ e Que deu origem ao livro L'emprise de l'organisation, lançado no Brasil, em 1987, com o título de $O$ poder das organizações: a dominação das multinacionais sobre um indivíduo. Enamoramento e identificação são, portanto, processos fundamentais à análise das massas organizadas. Este é mais um pressuposto fundamental da cultura humana.

Ao apresentar os pressupostos universais da cultura humana, segundo Freud, observo ser possível fazer uma reflexão à luz dos pressupostos básicos das culturas organizacionais segundo Schein.

Os pressupostos básicos das culturas organizacionais não são contrários a esses pressupostos universais. Evidentemente, cada organização tem suas especificidades, assim, não existem pressupostos básicos gerais.

Ao passo Que os pressupostos universais são instrumentos para decifrar os pressupostos básicos de cada organização, em particular, servindo para lhes dar forma, sem contudo tomar seu lugar. Por essa razão, a psicanálise pode ser muito útil na análise dos pressupostos básicos e da cultura organizacional .

\section{Cultura Organizacional na visão de Schein}

Para se compreender a cultura organizacional, é preciso investigar abaixo dos elementos visíveis da cultura, os artefatos e, também, dos elementos menos visíveis, mas, facilmente percebíveis os valores, procurando nos pressupostos básicos as origens do comportamento organizacional (Figura 1$)^{(6)}$.

Artefatos constituem o nível mais superficial e consciente no Qual estão todos os fenômenos visíveis, tangíveis e audíveis Que ocorrem como manifestação das camadas mais profundas (valores e pressupostos). São todos os elementos visíveis - ambiente construído, areuitetura, layout dos escritórios, tecnologia, produtos, logotipo, materiais de comunicação, comportamentos, estilo (por exemplo, hábitos de vestir), mitos e histórias contadas Que fazem parte da tradição da organização, documentos públicos (por exemplo, lista dos valores, missão, visão e documentos diversos), linguagem escrita e falada, cerimônias e rituais, costumes, recompensas e punições, bem como processos organizacionais Que se manifestam em rotinas ${ }^{(7)}$.

Os valores posicionam-se no nível intermediário entre o consciente e o inconsciente e são os conjuntos de princípios Que definem os artefatos. Valores são os fundamentos para os

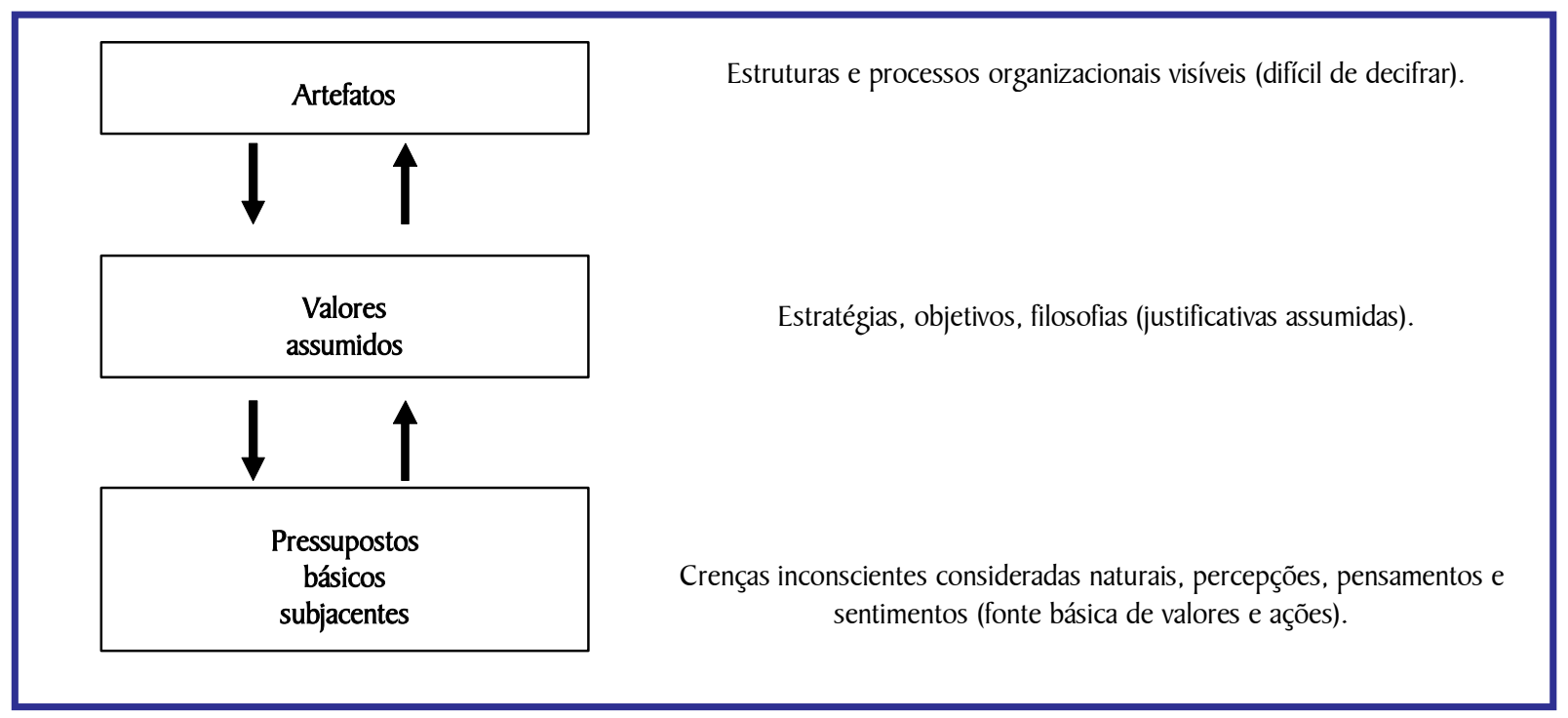

Figura 1. Os níveis da cultura e sua interação( ${ }^{(6)}$. 
julgamentos a respeito do Que está certo e errado, ou seja, o código ético e moral do grupo.

Portanto, os valores influenciam as escolhas do grupo. Schein utiliza o conceito de Argyris e Schön, de 1978, de espoused values, Que são os valores explicitados e manifestos, Que permitem predizer aQuilo Que as pessoas "dirão", mas não servem para compreender o Que realmente "farão"(8). Isso porque a incongruência entre o Que as pessoas dizem e o Que, realmente, fazem só se explica por meio do nível mais profundo e inconsciente, os pressupostos ${ }^{(7)}$.

Este último é o nível mais inconsciente e invisível, Que vai determinar por Que razões um grupo percebe, pensa e sente da maneira como o faz. Os pressupostos básicos são as respostas Que deram certo, referentes às Questões mais cruciais da sobrevivência do grupo Que, conseQüentemente, se tornaram valores e determinaram artefatos. Um conjunto de pressupostos inter-relacionados forma um paradigma cultural ${ }^{(7)}$.

Os paradigmas culturais apresentados por Schein são o objeto de estudo Que se optou para a comparação com os pressupostos básicos da cultura humana apresentados por Freud.

Por causa da necessidade humana de ordem e consistência, pressupostos são padronizados em algo Que pode ser denominado "paradigma cultural", Que une os pressupostos básicos sobre o ser humano, natureza e atividades. Portanto, um conjunto de pressupostos inter-relacionados Que formam um padrão coerente $^{(6)}$.

\section{Os paradigmas culturais de Schein}

Com base nos pressupostos resumidos acima, é apresentado um conjunto de cinco paradigmas culturais ${ }^{(6)}$, Que passaremos a descrever resumidamente.

A força da cultura: Pode ser observada pela homogeneidade e estabilidade dos elementos, pelo compartilhamento extensivo e intensivo desses elementos e pela existência de experiências fortes e intensas Que serviram para construir a cultura. Portanto, Quanto mais compartilhados e sedimentados os elementos de uma cultura (artefatos, valores, pressupostos), mais forte ela será.

$\boldsymbol{O}$ processo de aprendizagem em uma cultura: Schein aponta duas formas para o processo de aprendizagem em uma cultura. A primeira, é a capacidade desenvolvida em resolver problemas positivamente, intimamente ligada à capacidade de sobreviver. A segunda, é a capacidade de evitar situações de ansiedade, Que faz em desenvolver uma resposta padrão, sendo esta inconsciente.

Mudança cultural : As forças Que poderiam alterar a cultura são: o papel ambíguo exercido pela liderança, Que ora reforça os padrões estabelecidos, ora incentiva rompê-los. Uma fraca sedimentação da cultura, pela heterogeneidade no compartilhamento de significados, valores e pressupostos, em razão da presença de subculturas (culturas profissionais, setoriais, nacionais etc.).

Estabilidade ou mudança: Uma organização Que atinge maturidade ou declínio, apresentando excessiva estabilidade interna, enfrenta dificuldade em inovar ou fazer mudanças Que colidam com seus pressupostos, o Que torna a mudança um processo doloroso.

O papel da liderança: O líder é um gestor de significados, deve prover orientação aos grupos no sentido de encontrarem soluções para às Questões de sobrevivência externa. Entretanto, Quando essas soluções são novas formas de se resolver problemas, o líder deve gerenciar um binômio paradoxal - apontar e apoiar novas formas de resolver os problemas enfrentados, assegurando a sobrevivência externa e, ao mesmo tempo, promover a coesão interna e administrar a ansiedade advinda de ter de abrir mão do habitual e seguro, porém, ineficiente.

As subculturas: É preciso considerar Que uma cultura pode ter diversas "portas" de intercâmbio com nichos culturais onde está inserida, como o meio geográfico, o setor onde opera, as categorias profissionais Que fazem parte dela, etc., importando pressupostos Que, coexistindo na mesma organização, formam subculturas, podendo implicar em conflito.

\section{Paradigmas de Schein e os Pressupostos de Freud: uma Comparação}

Ciente da ousadia a Que me propus, a seguir apresento uma comparação, ainda de forma pouco aprofundada entre os paradigmas da cultura organizacional de Schein e os pressupostos básicos de Freud, buscando alguma evidência Que ligue esses dois enfoeues. Esta reflexão visa a nos auxiliar na localização dos pressupostos fundamentais da cultura humana e da cultura organizacional, evidenciando assim, Que este último campo de conhecimento pode ser desenvolvido com base em uma fonte única de motivações, calcada no comportamento humano estudado na Psicanálise.

\section{CONSIDERAÇÕES FINAIS}

Iniciei esta reflexão com a motivação estimulada por Motta, Quando indica Que Schein havia perdido a oportunidade de estudar os pressupostos básicos da cultura organizacional pela ótica da psicanálise, ciência, por natureza, do inconsciente. Este analisa uma discussão sobre os sistemas de controle social, verificando Que os sistemas estão presentes também nas organizações.

Com base no que foi exposto, perceber-se que Schein e Freud convergem para alguns pontos comuns Quando são adotados os pressupostos básicos como objeto de análise. No inconsciente do indivíduo, repousa a motivação para os comportamentos sociais, tanto nas massas como nas organizações.

Como indica Schein, só se define cultura se associada a um grupo social Que a possui e os elementos culturais desse grupo são as soluções aprendidas aos problemas vivenciados pelo grupo.

No entanto, as soluções só se tornam soluções Quando percebidas pelos indivíduos do grupo como sendo valiosas. Esse julgamento está apoiado em seus pressupostos básicos humanos, como estudados na Psicanálise de Freud.

Apesar das reflexões ainda pouco aprofundadas, fica visível o interesse em se valer da Psicanálise para o estudo e compreensão das organizações, sobretudo pela dificuldade de se lidar com os pressupostos básicos Que são interiores aos membros da organização.

Desejo Que esta proposta seja útil para um pensar reflexivo sobre os Pressupostos Universais da Cultura Humana e os Pressupostos da Cultura Organizacional. Esta reflexão nos remete à necessidade de um estudo mais profundo sobre o assunto. 


\begin{tabular}{|c|c|}
\hline Schein & Freud \\
\hline I. Força da Cultura: & Amor e Necessidade: \\
\hline $\begin{array}{l}\text { Homogeneidade e estabilidade dos elementos pelo } \\
\text { compartilhamento extensivo e existência de experiências } \\
\text { fortes e intensas. Capacidade coletiva desenvolvida em } \\
\text { resolver problemas. }\end{array}$ & $\begin{array}{l}\text { Com a família (proximidade dos parceiros sexuais - amor), surge a } \\
\text { necessidade de fornecer meios de subsistência a um número maior de } \\
\text { indivíduos que faz surgir novas técnicas mais aperfeiçoadas. O homem } \\
\text { descobre Que, por meio do trabalho, pode tornar sua sorte mais } \\
\text { satisfatória no mundo. }\end{array}$ \\
\hline 2. Processo de Aprendizagem: & Amor e Necessidade: \\
\hline $\begin{array}{l}\text { Resolver problemas positivamente (sobrevi-vência).Evitar } \\
\text { situações de ansiedade. }\end{array}$ & $\begin{array}{l}\text { Com a família (proximidade dos parceiros sexuais - amor), surge a } \\
\text { necessidade de fornecer meios de subsistência a um número maior de } \\
\text { indivíduos que faz surgir novas técnicas mais aperfeiçoadas. O homem } \\
\text { descobre Que, por meio do trabalho, pode tornar sua sorte mais } \\
\text { satisfatória no mundo. }\end{array}$ \\
\hline 3. Mudança Cultural: & Identificação e amor inibido: \\
\hline $\begin{array}{l}\text { As forças Que poderiam alterar a cultura são: o papel } \\
\text { ambíguo exercido pela liderança, Que ora reforça os padrões } \\
\text { estabelecidos, ora incentiva rompê-los; uma fraca } \\
\text { sedimentação da cultura, pela heterogeneidade no } \\
\text { compartilhamento de significados, valores e pressupostos, } \\
\text { em razão da presença de subculturas (culturas profissionais, } \\
\text { setoriais, nacionais, etc.); presença de turnover significativo } \\
\text { Que tenha o poder de aportar novos significados. }\end{array}$ & $\begin{array}{l}\text { A família tende a conservar-se unida e a desinteressar-se pelo resto do } \\
\text { grupo. Desvios da libido visam a diminuir a intensidade dos laços } \\
\text { familiares e a unir mais fortemente os membros das diversas famílias, } \\
\text { por intermédio da identificação e do amor inibido em seus fins. }\end{array}$ \\
\hline 4. Estabilidade ou Mudança: & Identificaçâo e amor inibido: \\
\hline $\begin{array}{l}\text { Uma organização Que atinge maturidade ou declínio, } \\
\text { apresentando excessiva estabili-dade interna, enfrenta } \\
\text { dificuldade em inovar ou fazer mudanças Que colidam com } \\
\text { seus pressupostos, o Que torna a mudança um processo } \\
\text { doloroso. }\end{array}$ & $\begin{array}{l}\text { A família tende a conservar-se unida e a desinteressar-se pelo resto do } \\
\text { grupo. Desvios da libido visam a diminuir a intensidade dos laços } \\
\text { familiares e a unir mais fortemente os membros das diversas famílias, } \\
\text { por intermédio da identificação e do amor inibido em seus fins. }\end{array}$ \\
\hline 5. Papel da Liderança: & Identificação recíproca: \\
\hline $\begin{array}{l}\text { O líder é um gestor de significados. O líder deve prover } \\
\text { orientação aos grupos no sentido de encontrarem soluções } \\
\text { para as Questões de sobrevivência externa. Entretanto, } \\
\text { Quando essas soluções são novas formas de se resolver } \\
\text { problemas, o líder deve gerenciar um binômio paradoxal - } \\
\text { apontar e apoiar novas formas de resolver os problemas } \\
\text { enfrentados, assegurando a sobrevivência externa, e, ao } \\
\text { mesmo tempo, promover a coesão interna e administrar a } \\
\text { ansiedade advinda de ter de abrir mão do habitual e seguro, } \\
\text { porém, ineficiente. }\end{array}$ & $\begin{array}{l}\text { Cada filho incorpora a sua parcela de "narciso", nenhum deles deixa de } \\
\text { ser o pai devorado. Este fato favorece e fortalece a reciprocidade na } \\
\text { identificação; entretanto, também a rivalidade é provocada. A } \\
\text { identificação de cada um com o líder é o fundamento da identificação } \\
\text { recíproca. }\end{array}$ \\
\hline 6. Subculturas: & Amor e Necessidade: \\
\hline $\begin{array}{l}\text { Numa cultura pode ter diversas "portas" de intercâmbio } \\
\text { com nichos culturais em Que está inserida, importando } \\
\text { pressupostos Que, coexistindo na mesma organização, } \\
\text { formam subculturas, podendo implicar conflito. Também na } \\
\text { convivência diária, subculturas podem surgir pela experiência } \\
\text { departamental, cujas áreas da organização fecham-se em } \\
\text { sub-culturas próprias com suas crenças compartilhadas } \\
\text { específicas. }\end{array}$ & $\begin{array}{l}\text { Com a família (proximidade dos parceiros sexuais - amor), surge a } \\
\text { necessidade de fornecer meios de subsistência a um número maior de } \\
\text { indivíduos que faz surgir novas técnicas mais aperfeiçoadas. O homem } \\
\text { descobre Que, por meio do trabalho, pode tornar sua sorte mais } \\
\text { satisfatória no mundo. }\end{array}$ \\
\hline
\end{tabular}

\section{Quadro 1. Comparação entre os paradigmas da cultura organizacional de Schein e os pressupostos básicos de Freud.}

\section{REFERÊNCIAS}

I. Motta FCP. Os pressupostos básicos de Schein e a fronteira entre a psicanálise e a cultura organizacional. In: Motta FCP, Freitas ME, organizadores. Vida psíQuica e organização. Rio de Janeiro (RJ): FGV; 2000. p. 75- 102.

2. Enriquez E. Imaginaire social, refoulement et répression dans les organisations. Connexions: EPI; 1972.
3. Capra F. As conexões ocultas: ciência para a vida sustentável. São Paulo (SP): Cultrix; 2002.

4. Schein E. Coming to a new awareness of organizational culture. Sloan Manag Rev 1984; 25(1): 3-16.

5. Freud S. O mal-estar na civilização. Rio de Janeiro (RI): Imago; 1997. 
6. Pagês M. L'emprise de l'organisation. Paris: Presses Universitaires de France; 1984.

7. Aguiar SMSP. A dinâmica entre raízes e asas: um estudo sobre organizações inovadoras [tese ]. São Paulo (SP): Escola de Administração e Economia, Fundação Getúlio Vargas; 2004.

8. Argyris C, Schôn DA. Organizational learning: a theory of action perspective. Reading (MA): Addison Wesley; 1978. 